\title{
A Novel Copper Complex with Multibridging Coordination Mode: Synthesis, Structure, Luminescent and Magnetic Properties
}

\author{
He-Lin Niu ${ }^{\mathrm{a}, \mathrm{b}, *}, \mathrm{Ji}^{-T a n g} \mathrm{Chen}^{\mathrm{b}}$, Ju-Zhou Zhang ${ }^{\mathrm{a}}$, Wei-Ran Cao ${ }^{\mathrm{a}}$ and Qian-Wang Chen ${ }^{\mathrm{a}, *}$ \\ ${ }^{a}$ Hefei National Laboratory for Physical Sciences at Microscale and Department of Materials Science \& Engineering, \\ University of Science and Technology of China, Hefei, 230026, People's Republic of China \\ ${ }^{b}$ Department of Chemistry, Anhui University, Hefei, 230039, People's Republic of China
}

\begin{abstract}
A novel three-dimensional (3D) metal-organic framework (MOF), $\left[\mathrm{Cu}_{5}\left(\mathrm{C}_{10} \mathrm{H}_{7} \mathrm{~N}_{2} \mathrm{O}_{2}\right)_{4}\left(\mathrm{~N}_{3}\right)_{2}\left(\mathrm{SO}_{4}\right)_{2}\right]_{\mathrm{n}}(\mathbf{1})$, was constructed by a hydrothermal process at $160^{\circ} \mathrm{C}$. The complex 1 exhibits strong emission at $396 \mathrm{~nm}$ in solid state. Importantly, the variable-temperature magnetic susceptibility study indicates that there exists strong antiferromagnetic interactions between the copper atoms with $C=0.87 \mathrm{~cm}^{3} \mathrm{~mol}^{-1} \mathrm{~K}$ and $\theta=-320.2 \mathrm{~K}$.
\end{abstract}

Key Words: Copper complex, hydrothermal synthesis, luminescent, magnetic property.

\section{INTRODUCTION}

The metal-organic frameworks ( MOFs) is now of great interest due to their intriguing topology architecture and significant potential applications in many fields such as gas storage [1-4], catalysis [5], luminescence [6,7] and magnetism [8-11]. The mainly strategy to obtain MOFs is employ organic groups as building blocks $[8,11]$, therefore, the organic ligand is a vital factor in the construction of MOFs. The carboxylicate group is an active block because of its eximious ability to mediate metal ions, and various complexes have been obtained [11, 12]. As an element for metal organic complex, the metal ion is very important because the resultant functionality might be determined not only the organic ligands but also the inorganic metal ions [11]. Accordingly, the selection of metal ions for MOFs is vital. As we know copper is a very attractive framework candidate to construct functional materials because of its capability to coordinate with unsaturated $\mathrm{N}-$, O- atoms. So far, a great number of MOFs containing copper atoms and carboxylicate group have been prepared, however, most of which display single property, either optical or magnetic property alone [11-14], so it is still a challenge to construct metal complexes with multi-functionality, e.g., magnetic and optical properties [15]. An attractive approach to obtain multi-functional materials might be design multifunctional organic ligand as building block. In this communication, a multal-property ligand, 4-(imidazol-1-yl) benzoic acid (HL) was selected, which contains an imidazole group and carboxylic acid group. The target product $\left[\mathrm{Cu}_{5}\left(\mathrm{C}_{10} \mathrm{H}_{7} \mathrm{~N}_{2} \mathrm{O}_{2}\right)_{4}\right.$

*Address correspondence to these authors at the Hefei National Laboratory for Physical Sciences at Microscale and Department of Materials Science \& Engineering, University of Science and Technology of China, Hefei, 230026, People's Republic of China; Tel: +86-551-3607292; Fax: +86-5513607292; E-mail address: cqw@ustc.edu.cn

Department of Chemistry, Anhui University, Hefei, 230039, People's Republic of China; Tel: +86-551-3607292; Fax: +86-551-3607292;

E-mail address: niuhelin@ustc.edu.cn
$\left.\left(\mathrm{N}_{3}\right)_{2}\left(\mathrm{SO}_{4}\right)_{2}\right]_{\mathrm{n}}$ was successfully obtained with the expected MOF and the desired luminescent and magnetic properties. Here we report its preparation, single crystal structure, thermal stability, luminescent and magnetic properties.

The complex 1 was obtained as green single crystals by the reaction of $\mathrm{HL}$ and copper sulfate in the presence of sodium azide via a hydrothermal process and a little powder product was obtained at the same time. The powder XRD experimental and computer-simulated patterns from the single crystal data using Mercury 1.4 software are shown in Fig. (1). The similarity of the powder XRD patterns indicates that the bulk synthesized materials and the as-grown crystals are homogeneous.

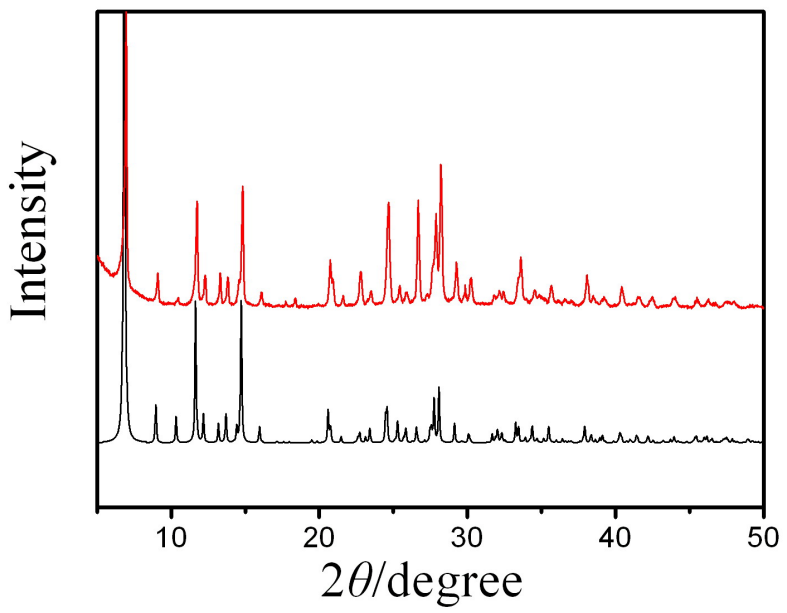

Fig. (1). The X-ray powder diffraction (XRD) pattern of 1. (Upper--experimental and Under--- computer-simulated).

The crystal structure of complex 1 is studied by singlecrystal X-ray diffraction, and result reveals a 3D framework that crystallizes in the monoclinic space group $C 2 / m$ (see supporting information). As shown in Fig. (2) the unit 
contains five $\mathrm{Cu}$ (II) ions, two azide anions, four imidazolylbenzoic acid groups and two sulfate anions, where two kinds of $\mathrm{Cu}$ (II) ions with different coordination environments were observed. The $\mathrm{Cu} 1$ is coordinated with four oxygen atoms of carboxyl groups, forming an oblong geometry with the cis-O-Cu-O angles from 86.02(5) ${ }^{\circ}$ to $93.98(5)^{\circ}$. While the $\mathrm{Cu} 2$ resides in a distorted tetragonal pyramid environment with apex occupied by one benzoic oxygen atom. The base surface is formed by two oxygen atoms are offered by sulfate ion and carboxylicate group, and the two nitrogen atoms are belonged to azide ion and imidazolyl, respectively. The two adjacent $\mathrm{Cu} 2$ are bridged by one azide anion with $\mu-1,1$ model (end-on model, EO model), while the distances and the angle as following: Cu2-N3 1.983(1) $\AA$, Cu2-N3$\mathrm{Cu} 2$ 133.07(7) ${ }^{\circ}$, respectively. The two $\mathrm{Cu} 2$ are also linked with $\mathrm{Cu} 1$ by carboxylic oxygen $(\mathrm{O} 2)$, and a triangle is formed by the metal atoms. The two metal triangles connect to each other with a vertex to give rise to a bow-tie type $\mathrm{Cu}_{5}\left(\mathrm{~N}_{3}\right)_{2}$ unit is symmetrically joined to adjacent cluster units by the bridge: imidazol-carboxylate group, the closest inerunit $\mathrm{Cu}$... Cu separation is 11.876(12) $\AA$ linked by it.

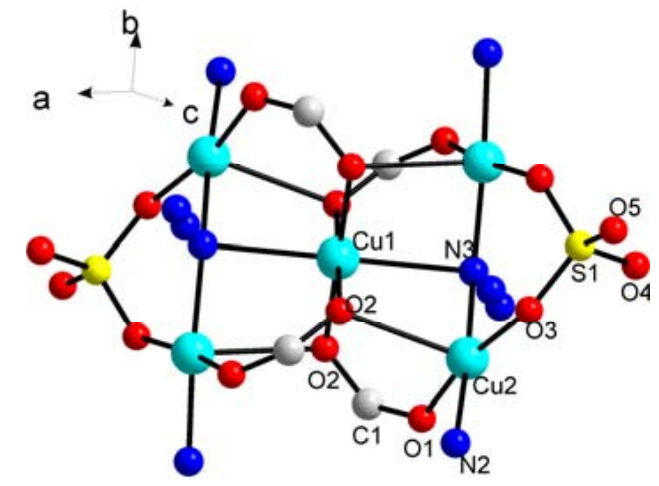

Fig. (2). Molecular structure and atom numbering of complex 1 (All hydrogen atoms are omitted for clarity).

The units are further extended to a 3D porous framework through the imidozal-carboxylate spacer. Every HL is connected with four copper atoms from different units, and there are two HL between every two units, and the two bridge groups are paralleled in alternate directions. The unique feature of $\mathbf{1}$ focuses on the $(a b)$ plane (Fig. (3)). It is shown that the network packs as a rhombus with the units occupied the crank points and grouped by the imidozalcarboxylate. The distance between the two central coppers is 14.12 (1) $\AA$ and the angles of the rhombus are $88.3^{\circ}$ and $91.7^{\circ}$, respectively. The distances between the diagonal entry are 19.669(3) $\AA$ and 20.263(27) $\AA$, but the difference of the apertures is obvious: the longer one is 19.669(3) $\AA$, the shorter is $13.449(11) \AA$ which is shortened by the sulfate anions.

To obtain the thermal stability information of $\mathbf{1}$, the complex was heated in air with $10^{\circ} \mathrm{C} / \mathrm{min}$, and the thermogravimetic analysis (TGA) is shown in Fig. (4). The initial weight loss corresponds to the removal of water from the crystals. Then the framework remains thermally stable up to $270{ }^{\circ} \mathrm{C}$, and then a dramatic weight loss occurs, which indicates the decomposition of $\left[\mathrm{Cu}_{5}\left(\mathrm{C}_{10} \mathrm{H}_{7} \mathrm{~N}_{2} \mathrm{O}_{2}\right)_{4}\left(\mathrm{~N}_{3}\right)_{2}\right.$
$\left.\left(\mathrm{SO}_{4}\right)_{2}\right]_{\mathrm{n}}$ accompanying with gas phase formation begins at the temperature.

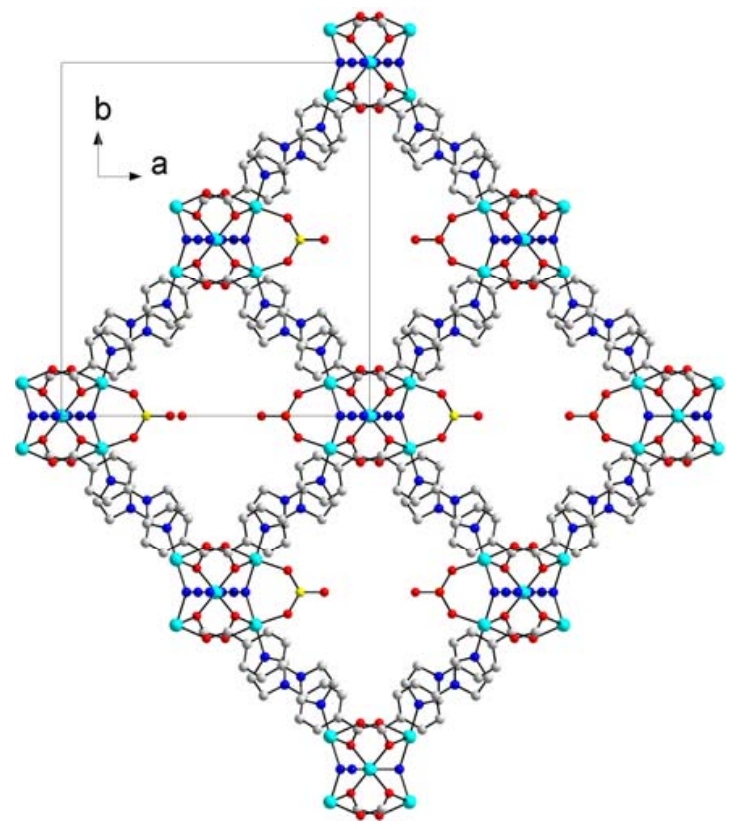

Fig. (3). The feature of complex $\mathbf{1}$ in the (a b) plane (All hydrogen atoms are omitted for clarity).

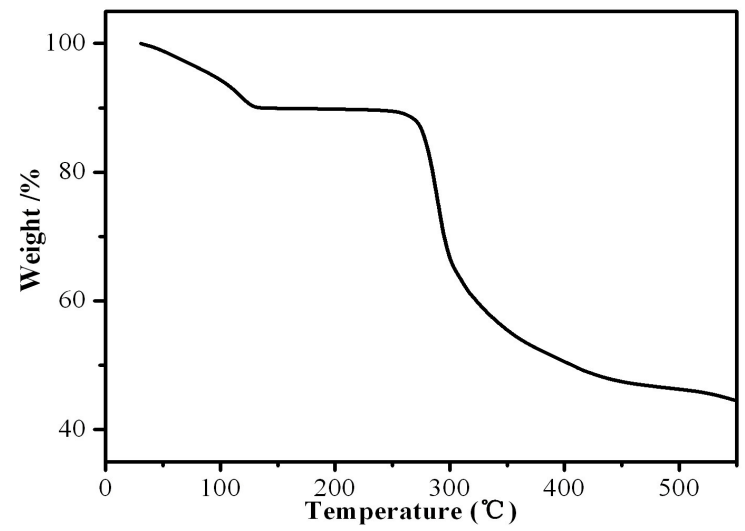

Fig. (4). The TG plot of complex 1.

The emission spectra of complex $\mathbf{1}$ and the ligand are given in Fig. (5). The complex shows an intense blue fluorescence emission band centering at $396 \mathrm{~nm}$, which might be due to the intraligand $\pi-\pi^{*}$ transitions, LMCT (ligand-to-metal-charge transfer) or MLCT (metal-to-ligand

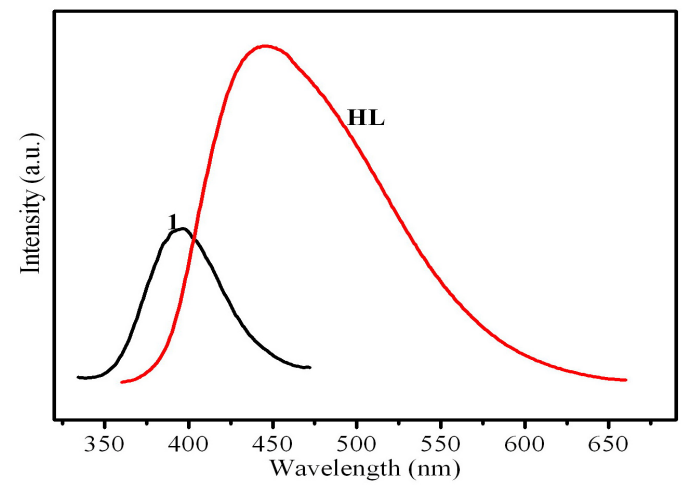

Fig. (5). The emission spectra of complex 1 and the ligand. 
charge transfer). Compared with that (444 $\mathrm{nm})$ of pure ligand, the band is blue-shifted by $48 \mathrm{~nm}$ with the obvious decrease of luminescent intensity, which reveals that the rigidity of the ligand is inflected by the metal atoms. An explanation has been given in our previous paper [15].

On particular interest is the capacity of bridging mode of azide to mediate magnetic interactions between the $\mathrm{Cu}$ ions bound to it. Thus, variable-temperature magnetic susceptibility measurement was carried out on a crystalline sample of the bridged complex from 4 to $300 \mathrm{~K}$ within a constant magnetic field of $100 \mathrm{Oe}$, the results are represented in Fig. (6), in the form of $\chi_{\mathrm{M}} T$ and $1 / \chi_{\mathrm{M}}$ versus $T$ plots. The value of $\chi_{\mathrm{M}} T$ per $\mathrm{Cu}(\mathrm{II})$ at $300 \mathrm{~K}$ is $0.39 \mathrm{~cm}^{3} \mathrm{~mol}^{-1} \mathrm{~K}$, slightly greater than isolated $\mathrm{Cu}(\mathrm{II})$ ion $\left(0.38 \mathrm{~cm}^{3} \mathrm{~K} \mathrm{~mol}^{-1}\right.$ and $\left.\mathrm{S}=1 / 2\right)$. They are almost equal. The $\chi_{\mathrm{M}} T$ value then starts to decrease dramatically with an increasingly pronounced slope, down to $0.16 \mathrm{~cm}^{3} \mathrm{~K} \mathrm{~mol}^{-1}$ at $70 \mathrm{~K}$. This shows that the system is dominated by antiferromagnetic interactions between the metal ions. Furthermore, the susceptibility data are fitted with modified Curie-Weiss law, with Curie constant $C=0.88 \mathrm{~cm}^{3} \mathrm{~mol}^{-1} \mathrm{~K}$ and Weiss constant $\theta=-320.2 \mathrm{~K}$. The negative value of Weiss constant $\theta$ further indicates the intensive antiferromagnetic interactions between $\mathrm{Cu}^{2+}$ ions. However, the value of $\chi_{\mathrm{M}} T$ increases slightly around $60 \mathrm{~K}$ indicating a very weak ferromagnetic state due to spin canting of the antiferromagnetically coupled $\mathrm{Cu}(\mathrm{II})$ ions [16]. The antiferromagnetic behavior between copper atoms has been predicted in the EO series as soon as the $\mathrm{Cu}-\mathrm{N}-\mathrm{Cu}$ valence angle is sufficiently large $\left(>104^{\circ}\right)$ [17], which has also been experimentally confirmed [18], and the antiferromagnetic interactions between metal atoms are also observed in our previous work [15]. Accordingly, the bridging action strengthens the antiferromagntic interactions between the metal atoms. At the same time, the organic group is distorted to connect the $\mathrm{Cu} 5$ units in the complex, which reduces the rigidity of the ligand, and thus give rise to the blue-shift of photoluminescence.

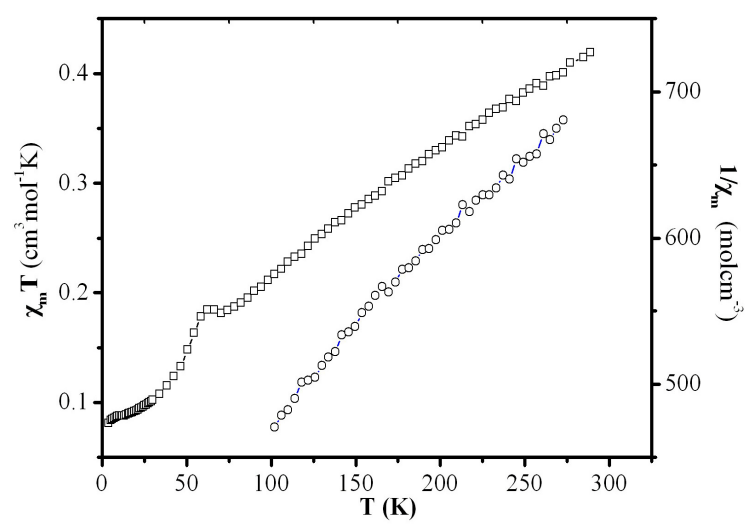

Fig. (6). Plots of both the magnetic susceptibility $\chi_{\mathrm{m}} \mathrm{T}(\square)$ and $1 / \chi_{\mathrm{m}}$ (O) versus temperature $(\mathrm{K})$ of $\mathbf{1}$.

In brief, a magneto-optical complex is successfully prepared via a hydrothermal method. The single-crystal Xray diffraction indicates the complex is a 3D framework. The magnetic measurement reveals there are antiferromagnetic interactions between the metal atoms are bridged by azide and imidozal-carboxylate, and the fluorescent measurement indicates the complex emits blue fluorescence at $396 \mathrm{~nm}$. Therefore, it is a feasible method to obtain multi-functional materials by select multi-propertied organic ligand as building blocks.

\section{ACKNOWLEDGEMENT}

We thank the foundations (Kj2008B270; 20771001; 10774138; 20070410790; 090414200) for support.

\section{REFERENCES}

[1] $\mathrm{Bu} \mathrm{XH,} \mathrm{Tong} \mathrm{ML,} \mathrm{Chang} \mathrm{HC,} \mathrm{et} \mathrm{al.} \mathrm{A} \mathrm{neutral} \mathrm{3D} \mathrm{copper} \mathrm{coordina-}$ tion polymer showing 1D open channels and the first interpenetrating NbO-Type network. Angew Chem Int Ed 2004; 43: 192-5.

[2] Ferey G, Millange F, Morcrette M, et al. Mixed-Valence Li/Febased metal-organic frameworks with both reversible redox and sorption properties. Angew Chem Int Ed 2007; 46: 3259-63.

[3] Ramsahye NA, Maurin G, Bourrelly S, Llewellyn P, Loiseauc T and Ferey G. Charge distribution in metal organic framework materials: transferability to a preliminary molecular simulation study of the $\mathrm{CO}_{2}$ adsorption in the MIL-53 (Al) system. Phys Chem Chem Phys 2007; 9: 1059-63.

[4] El-Kaderi HM, Hunt JR, Yaghi OM, et al. Designed synthesis of 3D covalent organic frameworks. Science 2007; 316: 268-72.

[5] Konsler RG, Karl J, Jacobsen EN. Cooperative asymmetric catalysis with dimeric salen complexes. J Am Chem Soc 1998; 120: 10780-1.

[6] Yam VW, Lam CH, Cheung KK. Syntheses and luminescence behaviour of dinuclear copper(I) selenolate and tellurolate complexes. X-Ray crystal structures of $\left[\mathrm{Cu}_{2}(\mu-\mathrm{dppm})_{2}(\mu-\mathrm{SePh})\right]$ $\mathrm{BF}_{4}$ and $\left[\mathrm{Cu}_{2}(\mu-\mathrm{dppm})_{2}(\mu-\mathrm{TePh})\right] \mathrm{BF}_{4}$. Chem Commun 2001; 6: 545-6.

[7] Liu B, Zhang XC and Wang YF. The syntheses, structures and fluorescent properties of two 3-D hydrogen-bonded frameworks constructed from monomeric $\mathrm{Zn}(\mathrm{II})$ and $\mathrm{Cd}(\mathrm{II})$ assemblies containing bitriazole. Inorg Chem Commun 2007; 2: 199-203.

[8] Sun CY, Zheng XJ, Gao S, Li LC and Jin LP. Multiple regulated assembly, crystal structures and magnetic properties of porous coordination polymers with Flexible Ligands. Eur J Inorg Chem 2005; 20: 4150-9.

[9] Jia HP, Li W, Ju ZF and Zhang J. Synthesis, structure, and magnetic properties of a novel mixed-bridged heterometal tetranuclear complex $\left[\mathrm{Mn}_{2} \mathrm{Ni}_{2}(\mathrm{MeOSalen})_{2}\left(\mu_{1,1}-\mathrm{N}_{3}\right)_{2}\left(\mathrm{~N}_{3}\right)_{2}\right]$. Inorg Chem Commun 2007; 4: 397-400.

[10] Zeng MH, Yao MX, Liang H, Zhang WX and Chen XM. A singlemolecule-magnetic, cubane-based, triangular $\mathrm{Co}_{12}$ supercluster. Angew Chem Int Ed 2007; 46: 1832-5.

[11] Zhang HT, Song Y, Li YX, Zuo JL, Gao S and You XZ. Threedimensional lanthanoid-containing coordination frameworks: structure, magnetic and fluorescent properties. Eur J Inorg Chem 2005; 4: 766-72.

[12] Liu H, Zhou H, Pan ZQ, Meng XG. A self-assembled pentanuclear single-stranded helicate based on the square-planar coordination geometries. Inorg Chem Commun 2007; 7: 805-7.

[13] Liu GF, Zhang WH, Chen Y, Liu D and Lang JP. Solvothermal synthesis and crystal structure of a luminescent 2D copper(I) coordination polymer with a $(3,4)$-connected net. Inorg Chem Commun 2007; 9: 1049-53.

[14] Miao ZX, Li MX, Shao M and Liu HJ. Syntheses, crystal structures and magnetic property of two azido-bridged coordination polymers with 1,2-diaminocyclohexane as co-ligand. Inorg Chem Commun 2007; 9: 1117-20.

[15] Zhang JZ, Cao WR, Pan JX and Chen QW. A novel two-dimensional square grid cobalt complex: Synthesis, structure, luminescent and magnetic properties. Inorg Chem Commun 2007; 10:1360-4

[16] Li JR, Yu Q, Tao Y and Bu XH. An azido- $\mathrm{Cu}^{\mathrm{II}}$-triazolate complex with utp-type topological network, showing spin-canted antiferromagnetism. Chem Commun 2007; 25: 2602-4. 
[17] Ruiz E, Cano J, Novoa JJ and Alvarez S. Magnetic coupling in end-to-end azido-bridged copper and nickel binuclear complexes: A Theoretical Study. Inorg Chem 2000; 39: 3221-9.

[18] Thompson LK, Tandon SS and Manuel ME. Magneto-structural correlations in $\mu_{2}-1,1$-azide-bridged dicopper(II) complexes. 2 . Dominant antiferromagnetic coupling with azide bridge angles exceeding $108^{\circ}$. X-ray Structures of $\left[\mathrm{Cu}_{2}(\mathrm{PAP})\left(\mu_{2}-\mathrm{N}_{3}\right) \mathrm{Br}_{3}\right] \mathrm{CH}_{2} \mathrm{Cl}_{2}$, $\left[\mathrm{Cu}_{2}(\mathrm{PAP} 6 \mathrm{Me})\left(\mu_{2}-\mathrm{N}_{3}\right)\left(\mu_{2}-\mathrm{Br}\right) \mathrm{Br}_{2}\right] .1 .68 \mathrm{H}_{2} \mathrm{O},\left[\mathrm{Cu}_{2}(\mathrm{PAP} 6 \mathrm{Me})\left(\mu_{2}-\mathrm{N}_{3}\right)\right.$ $\left.\left(\mu_{2}-\mathrm{H}_{2} \mathrm{O}\right)\left(\mathrm{NO}_{3}\right)_{2}\right]\left(\mathrm{NO}_{3}\right) \cdot 0.75 \mathrm{CH}_{3} \mathrm{OH},\left[\mathrm{Cu}_{2}(\mathrm{PAN})\left(\mu_{2}-\mathrm{N}_{3}\right)\left(\mu_{2}-\mathrm{NO}_{3}\right)\right.$ $\left.\left(\mathrm{NO}_{3}\right)_{2}\right] \cdot \mathrm{CH}_{3} \mathrm{OH} \cdot \mathrm{CH}_{3} \mathrm{CN}$, and $\left.\mathrm{Cu}_{2}(\mathrm{PPD} 35 \mathrm{Me})\left(\mu_{2}-\mathrm{N}_{3}\right) \mathrm{Br}_{3}\left(\mathrm{CH}_{3} \mathrm{OH}\right)\right]$. Inorg Chem 1995; 34: 2356-66.

Received: February 19, 2009

Revised: March 19, 2009

Accepted: April 6, 2009

() Niu et al.; Licensee Bentham Open.

This is an open access article licensed under the terms of the Creative Commons Attribution Non-Commercial License (http://creativecommons.org/licenses/by$\mathrm{nc} / 3.0 /$ ) which permits unrestricted, non-commercial use, distribution and reproduction in any medium, provided the work is properly cited. 